\title{
Exploring the role of enhanced weathering in overshoot scenarios
}

\author{
KATSUMASA TANAKA ${ }^{1}$, S. DANIEL GOLL ${ }^{1}$ AND \\ PHILIPPE CIAIS ${ }^{2}$ \\ ${ }^{1}$ Laboratoire des Sciences du Climat et de l'Environnement
} (LSCE)

${ }^{2} \mathrm{CEA} / \mathrm{CNRS} /$

Presenting Author: katsumasa.tanaka@1sce.ipsl.fr

To avoid overshooting the temperature targets of the Paris Agreement, we investigate the potential role of "enhanced weathering," an emerging and arguably promising idea of applying rock powder to soils to enhance carbon-absorbing weathering processes as well as to increase biological carbon sequestration due to improved soil fertility. Enhanced weathering, a method for negative $\mathrm{CO}_{2}$ emissions with low technological hurdles and risks, may serve as a way to eliminate overshoot. This raises the questions as to: to eliminate a temperature overshoot of a certain magnitude, when enhanced weathering should start, how large it needs to be strengthened at maximum, and how much are the associated economic costs.

To answer these questions, we employ the Aggregated Carbon Cycle, Atmospheric Chemistry, and Climate model (ACC2) [1]. ACC2 describes major physical and biogeochemical processes in the global carbon cycle and climate system as well as considers economic costs of climate mitigation. More specifically, the land and ocean carbon cycle is described by a box model. The physical climate is represented by a heat diffusion model. The economy component is a set of global marginal abatement cost (MAC) curves for $\mathrm{CO}_{2}, \mathrm{CH}_{4}$, and $\mathrm{N}_{2} \mathrm{O}$. This model allows to identify cost-effective emission pathways to achieve goals such as the $2{ }^{\circ} \mathrm{C}$ target [2]. We implement enhanced weathering as a mitigation option in ACC2 based on the output of the ORCHIDEE land surface model describing the carbon, nitrogen, and phosphorus cycles of global vegetation [3]. The economic costs of applying enhanced weathering are also considered in ACC2 as part of the calculation of mitigation costs using the MAC curves. By applying this new model setup, we will calculate the cost-effective way of using enhanced weathering on overshoot scenarios and explore the usefulness of enhanced weathering in the mitigation portfolio on overshoot pathways.

References

[1] Tanaka, Kriegler, Bruckner, Hooss, Knorr \& Raddatz (2007) Max Planck Institute for Meteorology Report 40. http://hdl.handle.net/11858/00-001M-0000-0011-FB8C-3

[2] Tanaka \& O'Neill (2018), Nature Climate Change 8, 319324.

[3] Goll, Vuichard, Maignan, Jornet-Puig, Sardans, Violette, Peng, Sun, Kvakic, Guimberteau, Guenet, Zaehle, Penuelas, Janssens \& Ciais (2017), Geoscientific Model Development 10, 3745-3770. 